\title{
Detection of TORCH pathogens in children with congenital cataracts
}

\author{
$\mathrm{BIN} \mathrm{LU}^{1}$ and $\mathrm{YABO} \mathrm{YANG}^{2}$ \\ ${ }^{1}$ Department of Ophthalmology, Children's Hospital, Zhejiang University School of Medicine, Hangzhou, Zhejiang 310003 ; \\ ${ }^{2}$ Department of Ophthalmology, The Second Affiliated Hospital, Zhejiang University School of Medicine, \\ Hangzhou, Zhejiang 310009, P.R. China
}

Received December 13, 2014; Accepted March 7, 2016

DOI: $10.3892 / \mathrm{etm} .2016 .3348$

\begin{abstract}
The aim of the present study was to investigate the correlation between infection rates with TORCH pathogens including toxoplasma, rubella virus, cytomegalovirus, and herpes simplex virus (HSV) I and II and congenital cataracts. In total, the data from 69 children with congenital cataract treated at the Children's Hospital of the Zhejiang University School of Medicine between May 2006 and September 2013 were examined, including the complete serum test results for immunoglobulin ( $\mathrm{Ig}) \mathrm{G}$ and $\mathrm{IgM}$ that target TORCH pathogenic antibodies. These results were compared with the antibody levels of 5,914 children in a control group. Using SPSS 19.0 software, variance equation Levene tests, mean equation $t$ tests, and completely randomized design of four tables $\chi^{2}$ tests were applied. The HSV II IgG positivity rates significantly differed between the cataract and control groups. These results suggested that HSV may be one of the pathogenic viruses that leads to congenital cataracts.
\end{abstract}

\section{Introduction}

Congenital cataract is a severe eye disease with a complex pathogenesis that causes blindness in children. The development of genomics research has allowed the in-depth study of the cataract pathogenesis $(1,2)$. During embryogenesis, viral and parasitic infections may influence the development of congenital cataract (3-5). Lifestyle changes, including changes in modern human sexuality and co-habitation with pets has resulted in increased herpes simplex virus (HSV) and toxoplasma (TOX) infection rates among pregnant women $(6,7)$. In addition, the incidence of adverse pregnancy outcomes, including congenital cataracts, has also increased (6). A recent survey by Li et al (8) reported a primary infection of TOX,

Correspondence to: Dr Bin Lu, Department of Ophthalmology, Children's Hospital, Zhejiang University School of Medicine, 57 Zhugan Lane, Hangzhou, Zhejiang 310003, P.R. China

E-mail: ybdoccn@163.com

Key words: TORCH, congenital cataract, children rubella virus (RV), cytomegalovirus (CMV) or HSV, abbreviated as TORCH infection, positivity rate of $17.2 \%$ among pregnant women living in Beijing, with the highest positivity rates being those of HSV immunoglobulin ( $\mathrm{Ig}) \mathrm{M}$. These infections with TORCH during pregnancy can produce an embryopathy characterized by limb hypoplasia, eye and brain damage, skin lesions, and even death. The infection typically gains access to the fetus via the placenta (8). Following an investigation into the lifestyle habits of 2,356 pregnant women from 2005 to 2007 , including a survey on pets, raw food diets, living conditions, and other lifestyle habits, Thaller et al (9) demonstrated that there was an increased incidence of infection with TOX among pregnant women living in rural areas who ate homemade bacon. Following infection, the immune systems of the pregnant women produce a series of antibodies that are transferred to the developing fetus through the placenta, and remain present for a specific period of time following birth (10). Mahalakshmi et al (10) reported an association between IgM antibodies against TORCH pathogens and congenital cataracts in a retrospective study of 593 children in Tamil Nadu Hospital of Chennai, India, using ELISA.

The present study aimed to determine the positivity rates of TORCH serum IgG and IgM antibodies in children with congenital cataracts, and compare these with the positivity rates in the non-TORCH control group; this includes assessment of the differences between single and double eye disease which are associated with TORCH infection. The study also examined any statistically significant differences in HSV II IgG levels in children with congenital cataracts.

\section{Materials and methods}

Study subjects. The study population consisted of a cataract and a control group. The cataract group included 69 children with congenital cataracts who were diagnosed and admitted to the Children's Hospital, Zhejiang University School of Medicine (Hangzhou, China) for surgical treatment. There were 33 boys and 36 girls, aged 1 month and 9 days to 7 years and 7 months, with an average age of $19.57 \pm 22.164$ months. Among these, 32 cases of children with monocular cataracts and 37 cases of children with eye cataracts in both eyes were included. The human immunodeficiency virus (HIV) and Treponema pallidum-specific passive hemagglutination assays 
(TPHA) of the children were negative. Cases that had a clear family history of genetic cataracts were excluded from the study.

The control group consisted of 5,914 randomly selected outpatients who were treated during the same time period (between years 2006 and 2013), including 2,843 boys and 3,071 girls aged 1 month to 7 years and 5 months (average age, $18.98 \pm 23.855$ months). Their family genetic histories and HIV and TPHA test results were unknown.

All cases were TORCH-positive or negative and all suspicious cases (weak positive of suspected positive cases) reported as positive were excluded. The study was conducted in accordance with the declaration of Helsinki, and with approval from the Ethics Committee of the Children's Hospital, Zhejiang University School of Medicine (Hangzhou, China). Written informed consent was obtained from all the legal guardians of the participants.

Collection of blood samples. A total of 1-2 ml peripheral fresh vein serum was collected from each patient and placed in anticoagulant tubes (BD Biosciences, Franklin Lakes, NJ, USA) at room temperature for $\leq 8 \mathrm{~h}$. The samples that would be used for testing after $8 \mathrm{~h}$ were immediately stored at $2-10^{\circ} \mathrm{C}$, and those that were expected to be tested after $24 \mathrm{~h}$ were immediately stored at $-20^{\circ} \mathrm{C}$. All samples were tested within 2 days of collection.

ELISA. ELISA was conducted using the following immunoglobulin (Ig)G and IgM test kits (Trinity Biotech Plc, Jamestown, NY, USA); TOX-IgM (cat. no. 2325160); TOX-IgG (cat. no. 2325100); RV-IgM (cat. no. 2325360); RV-IgG (cat. no. (2325300); CMV-IgM (cat. no. 2325260); CMV-IgG (cat. no. 2325200); HSV1-IgM (cat. no. 2325460); HSV1-IgG (cat. no. 2325400); HSV2-IgM (cat. no. 2325560) and HSV2-IgG (cat. no. 2325500).

Detection step. Measuring process of serum TORCH antibody (CMV-IgG was the example, and the measuring procedure of other pathogens was the same). The Immune Status Ratio (ISR) for each specimen was calculated by dividing the specimen optical density value by the Cutoff Calibrator Value determined by multiplying the Correction Factor by the mean Calibrator optical density.

A $50 \mathrm{ml} 20 \mathrm{X}$ concentrated buffer solution I (Tris-buffered saline with Tween 20 and ProClin as a preservative) was diluted with $1 \mathrm{~L}$ deionized water and mixed thoroughly. Gen5 version 2.0 (BioTek, Winooski, VT, USA) and BioTek Eon Microplate Spectrophotometer (BioTek) was used for the assay procedure.

The required number of microtest strips were placed onto a micropore frame. A total of 4 quality control materials and calibrators (1 negative quality control material, 2 calibrators, and 1 positive quality control material) were used in each test. A reagent blank was also prepared for each experiment. The quality control materials and calibrators were used to confirm that the software and photometer were configured correctly. Desiccant was added to the unused microtest strips, which were placed into a sealable bag and immediately stored at $4^{\circ} \mathrm{C}$.

The test serum, quality control materials, and calibrators were diluted with serum diluent (provided in CMV IgG
ELISA kit) at a 1:81 ratio $(10+800 \mu \mathrm{l})$ and agitated. A total of $100 \mu \mathrm{l}$ of the diluted calibrators, quality control materials, and serum were added to each well (96 well microassay plate), and $100 \mu \mathrm{l}$ sample dilution was added to the blank well. The quality control materials and calibrators were confirmed to be correctly configured for the software and photometer. Each well was incubated at room temperature $\left(21-25^{\circ} \mathrm{C}\right)$ for $30 \pm 2 \mathrm{~min}$.

Subsequently, the liquid in the micropores was removed, and 250-300 $\mu \mathrm{l}$ diluted buffer solution (serum diluent with $0.1 \%$ ProClin as a preservative) was added to each hole. The microtest strips were washed once with washing buffer (provided in CMV IgG ELISA kit) using an automatic plate washer. The liquid was removed from the micropores and the microplate was placed upside down on absorbent paper to remove the remaining liquid, and washed five times. Following the final rinse, the microplate was again placed upside down on absorbent paper to remove all the remaining liquid. Taking care to avoid the formation of bubbles, $100 \mu \mathrm{l}$ goat anti-human IgG horseradish-peroxidase enzyme conjugate was added to each well, including the blank well. Each well was incubated at room temperature $\left(21-25^{\circ} \mathrm{C}\right)$ for $30 \pm 2 \mathrm{~min}$, then washed as described above. Tetramethyl benzidine chromogenic agent substrate (100 $\mu \mathrm{l}$; Trinity Biotech Plc) was added to each well, including the blank well. Each well was incubated at room temperature $\left(21-25^{\circ} \mathrm{C}\right)$ for $15 \pm 2 \mathrm{~min}$. A total of $100 \mu \mathrm{l}$ stop buffer $(1 \mathrm{~N} \mathrm{H} 2 \mathrm{~S} 04)$ was then added to each well to terminate the reaction, including the blank well. The microplate was gently agitated to allow thorough mixing. The absorbance of each well was read $1 \mathrm{~h}$ following the addition of the stop buffer using a Victor ELISA analyzer (BioTek) at a wavelength of $450 \mathrm{~nm}$. The absorbance of the reagent blank at $450 \mathrm{~nm}$ was $<0.150$. If the reagent blank absorbance was $\geq 0.150$, the experiments were repeated.

Calculation and interpretation of the experimental results. The mean optical density (OD) values of the reference samples (the two calibrators) were calculated. To account for day-to-day fluctuations in assay activity due to room temperature and timing, Trinity Biotech Plc (Bray, Ireland) was used to determine the correction factor. The critical correction value was the mean absorbance value of the calibrator calculated in the first step multiplied by the correction factor. The ISR value of each sample was the OD value of each sample divided by the critical correction value. This is a qualitative kit, and the reference values were the cut-off values and the ISR values. The ISR values were used to determine the test results (Table I). The results of all antibody tests assessed in the current study were based on the ISR values. The following formulae were used: Cut-off value = mean OD value of the calibrator $\mathrm{x}$ correction factor; ISR value $=$ OD value of patient serum samples/cut-off value.

Statistical analysis. SPSS 19.0 software (IBM SPSS, Armonk, NY, USA) was used for all statistical analyses. The ages of the children were compared using independent sample t-tests, and completely randomized design of four tables $\chi^{2}$ tests were applied to gender in order to compare the positivity rates of anti-TORCH antibodies between the cataract and control groups. According to the $2 \times 2$ tables $(0.0 \%)$, the theoretical 
Table I. Interpretation of the ISR values.

\begin{tabular}{lll}
\hline ISR value & Result & \multicolumn{1}{c}{ Interpretation } \\
\hline$\leq 0.9$ & Negative & $\begin{array}{l}\text { Following ELISA, anti-CMV IgG } \\
\text { antibody was not detected, and the } \\
\text { individual was thus considered to be } \\
\text { uninfected by CMV, which is the } \\
\text { pathogen with which susceptible } \\
\text { people are first infected. } \\
\text { 0.91-1.09 }\end{array} \quad \begin{array}{l}\text { Suspected } \\
\text { The sample will require re-testing. }\end{array}$ \\
& $\begin{array}{l}\text { Positive } \\
\text { Following ELISA, anti-CMV IgG } \\
\text { antibodies were detected, which } \\
\text { suggested that the patient was } \\
\text { recently or currently infected. These } \\
\text { individuals may be at risk of the } \\
\text { spread of CMV infection, but they } \\
\text { were not necessarily infected at } \\
\text { the time of the test. }\end{array}$
\end{tabular}

Interpretation of CMV IgM test results: ISR value $\leq 0.9$, negative results (anti-CMV IgM antibody could not be detected); ISR value $=0.91-1.09$, it was unclear whether the results were positive or negative, and the samples were re-tested; ISR value $\geq 1.10$, positive results that suggested that anti-CMV IgM antibody levels were high, indicating a recent infection. CMV, cytomegalovirus; ISR, immune status ratio; ELISA, enzyme-linked immunosorbent assay; Ig, immunoglobulin.

frequency was calculated, and based on this minimum expected count the appropriate P-values for Pearson $\chi^{2}$, calibration $\chi^{2}$, and Fisher's exact tests were determined. Data were presented as the mean \pm standard deviation. $\mathrm{P}<0.05$ was considered to indicate a statistically significant result.

\section{Results}

General characteristics. The age and gender of the cataract and control groups had a skewed (non-normal) distribution (Fig. 1). Due to the fact that there were $>50$ samples, Pearson $\chi^{2}$ tests were used to compare the gender between the groups, whereas independent samples t-tests were used to compare age. The results of both tests showed no significant differences $(\mathrm{P}>0.051$ Table II).

Comparison of TORCH antibodies between the cataract and control groups. The rates of anti-HSV II IgG antibody positivity were significantly higher in children with cataracts $(\mathrm{P}=0.014)$; however, the differences in anti-HSV II IgM positivity rates between these groups was not statistically significant $(\mathrm{P}>0.05)$. Similarly, differences in the expression levels of $\mathrm{IgG}$ and $\mathrm{IgM}$ specific to other TORCH pathogens were also not statistically significant ( $\mathrm{P}>0.05$; Tables III and IV).

Comparison of TORCH pathogen positivity rates between children with monocular cataracts and children with binocular cataracts. The results of the $\chi^{2}$ tests demonstrated that no significant differences in the incidences of anti-TORCH
IgG and IgM antibodies were present between children with monocular and binocular congenital cataracts $(\mathrm{P}>0.05$; Tables V and VI).

\section{Discussion}

Previous studies carried out on congenital cataracts caused by viral infections have predominantly focused on the RV (11). With regard to other pathogens, Madhavan et al (12) reported that HSV infection was associated with patients with congenital cataracts in India; Raghu et al (13) demonstrated that congenital cataracts were associated with HSV I infections; Shyamala et al (14) detected HSV II DNA in children with congenital cataracts; and Kuot et al (15) reported a case of a patient with early-onset Fuchs' corneal endothelial dystrophy associated with congenital cataracts and keratitis due to HSV infection. In addition, Hutchison et al (16) previously established an animal cataract model of Toxoplasma gondii infection.

Infections with TORCH pathogens such as HSV may affect the ectodermal tissues (17), from which the lens is derived. The author assumes that lens opacification after birth and existence of additional factors are likely the result of intrauterine TORCH infections, which can be identified by the detection of maternal IgG antibodies in the baby. However, IgG and IgM antibodies after birth are derived from the immune response generated by self-infection in children; therefore, the presence of IgM antibodies after birth may not be sufficient to definitively correlate the presence of TORCH pathogens with the development of congenital cataracts. The results of the analysis of both $\operatorname{IgG}$ and $\operatorname{IgM}$ antibodies in the present study correlated with the results of Mahalakshmi et al (10). However, lens opacification after birth in infants positive for IgG antibodies may reflect past infection, whereas for children with congenital cataract for whom lens opacification is not present at birth, congenital cataract is defined as cataract occuring within 1 years after birth. Some children with congenital cataract at birth have transparent lens, and these children typically have TORCH pathogens marked by IgM. These children are likely to have an intrauterine infection or a mother with an infection, and may harbor disease-causing viruses but without detectable clinical symptoms. Upon a second virus infection, the immune system would be re-activated, triggering a number of unknown biological mechanisms, finally leading to the appearance of clinical symptoms, such as cloudy lens.

In a study of HSV I primary infections, Lafaille et al (18) observed that children with toll-like receptor 3 (TLR3) innate immune defects were more prone to developing HSV I encephalitis. Impaired TLR3 and UNC-93B, which depend on interferon- $\alpha / \beta$ innate immunity, can lead to HSV I manifestations in the central nervous system, particularly in neurons and oligodendrocytes (18). Nerve fibers have yet to be identified in the lens, although if present these may serve as a major route for HSV neuronal infection, and may also influence lens development via other direct or indirect means, such as keratitis, uveitis and retinitis (19). HSV II primarily leads to skin infections of the genital tract and below the waist, and infection of the fetus during pregnancy is more likely to occur (20). In the present study, the comparison of children with cataracts and the relatively large sample sizes demonstrated that anti-HSV I 

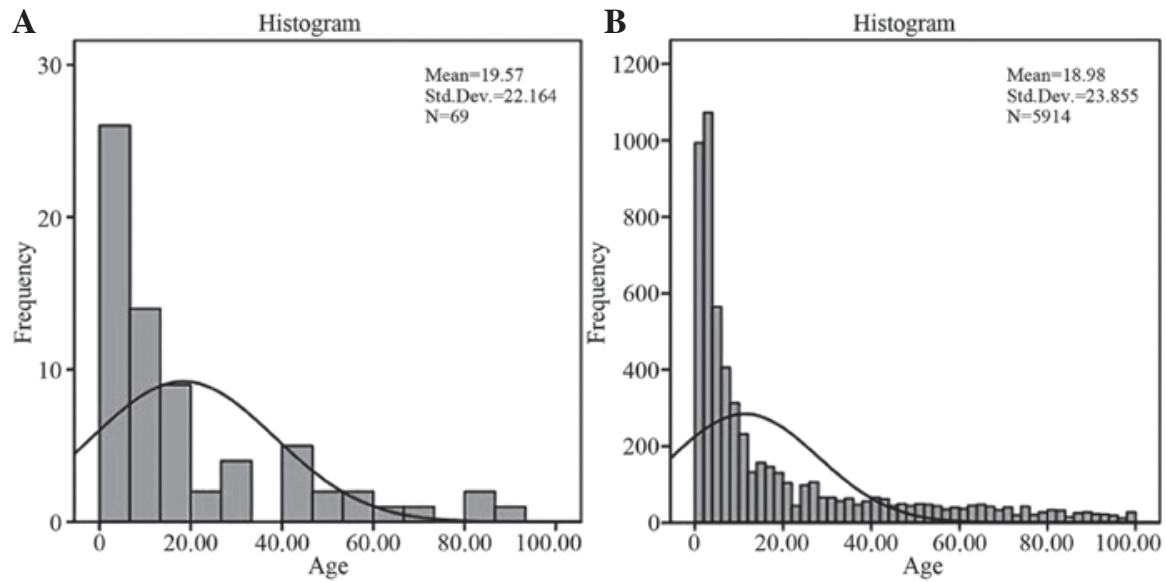

Figure 1. Age distribution of the cataract and control groups. (A) Cataract group; (B) control group (units/month).

Table II. Age and gender of the cataract and control groups.

\begin{tabular}{lcc}
\hline Parameter & Cataract group & Control group \\
\hline Cases & 69 & 5,914 \\
Gender & & \\
Female & $36 / 69(52.2 \%)$ & $2843 / 5914(48.1 \%)$ \\
Male & $33 / 69(47.8 \%)$ & $3071 / 5914(51.9 \%)$ \\
Age (months) & $19.57 \pm 22.164$ & $18.98 \pm 23.855$ \\
\hline
\end{tabular}

Constituent ratio of male and female gender in the two groups, $\chi^{2}=0.002, \mathrm{P}=0.968$; comparison of ages between the two groups, $\mathrm{t}=0.202, \mathrm{P}=0.840$.

antibody expression levels were not high; however, anti-HSV II IgG levels were higher, suggesting that HSV infections may be risk factors of congenital cataracts.

Based on independent viral infection rates, Malathi et al (21) suggested that $10 \%$ of congenital cataracts were due to RV infection, and that IgM antibodies in children $<6$ months of age with congenital cataracts may be associated with RV. Highlighting the diversity of rubella syndrome, Ferrini et al (22) reported the case of a 12-month-old girl who developed a cataract 3 months after receiving the RV vaccine. Rubella infection rates were low in this study, and did not differ significantly between groups.

The most common symptom of the ocular manifestations of congenital toxoplasmosis is chorioretinitis (92\%), followed by small eye and squint, iridocyclitis, cataract and glaucoma (23). Vandenbroucke et al (24) reported a case of congenital cataracts in a baby positive for TOX infection. However, TOX testing in the present study revealed a low incidence of TOX infection, and there were no statistically significant differences between groups.

Thibault et al (25) suggested that there was no causal association between CMV infection and congenital cataracts. However, a study of factors associated with cataract protein gene mutations including heat shock factor 4 (Hsf4b) conducted by Zhang et al (26) suggested that Hsf4b participates in the negative regulation of the CMV promoter as a downstream monitoring factor with a dual function as a transcriptional activator and inhibitor, affecting the channel activity of the lens protein and other biological substances. In addition, $\mathrm{CMV}$ often causes retinal choroidal inflammation, an eye inflammation that leads to changes in the lens environment, which is the basis for the formation of cataracts. Tran et al (27) demonstrated that $26 \%$ of necrotizing retinitis had cataracts. Given the higher levels of anti-CMV antibodies in the cataract group compared with the control group in the current study (CMV IgM: 15.50 vs. $11.80 \%$; CMV-IgG: 23.20 vs. $17.00 \%$ ) we recommend preventive treatment.

Traditionally, pediatric ophthalmology considers bilateral cataracts in children to be due to genetic and systematic diseases, whereas monocular cataracts are attributed to local phenomenon or abnormal development of other ocular structures (28). In the present study, there were no significant differences in the expression levels of TORCH pathogenic antibodies among children with monocular and binocular congenital cataracts.

Previous studies have demonstrated that the in vivo expression levels of anti-TORCH antibodies in women varies according to country and region. Lito et al (29) reported anti-RV IgG positivity rates of $93.3 \%$, anti-TOX IgG rates of $25.7 \%$ and anti-CMV IgG rates of $62.4 \%$ among pregnant women in Portugal; Vilibic-Cavlek et al (30) reported anti-TOX IgG seropositivity rates of $29.1 \%$, RV rates of $94.6 \%$, CMV rates of $75.3 \%$, HSV I rates of $78.7 \%$, and HSV II rates of $6.8 \%$ among pregnant women in Croatia. Anti-TOX and CMV IgM positivity rates were 0.25 and $0.09 \%$ respectively, HSV I and HSV II were $1.2 \%$, and RV rates were $0 \%$. Sen et al (31) reported anti-CMV IgM positivity rates of $19.4 \%$, anti-RV IgM rates of $30.4 \%$, anti-CMV IgM rates of $34.7 \%$, and anti-HSV II IgM rates of $33.5 \%$ in Indian women. Puccio et al (32) reported CMV infection rates of 62.5 and $91.4 \%$ among residents and immigrants in Italy, respectively. These results indicate that the areas with the highest anti-TORCH IgG antibody positivity rates in pregnant women were predominantly economically developed areas. Conversely, the areas with the highest anti-TORCH $\operatorname{IgM}$ antibody positivity rates in pregnant women in developing countries were predominantly located in underdeveloped communities, in which the occurrence of congenital cataracts was also higher (33). These results also suggest that 
Table III. Positive rates of anti-TORCH pathogen IgG antibodies in the cataract and control groups.

\begin{tabular}{lcccccc}
\hline Group & N & HSV II IgG & HSV I IgG & RV IgG & TOX IgG & CMV IgG \\
\hline Cataract group & 69 & $5 / 69(7.20 \%)$ & $7 / 69(10.10 \%)$ & $4 / 69(5.80 \%)$ & $0 / 69(0.00 \%)$ & $16 / 69(23.20 \%)$ \\
Control group & 5,914 & $127 / 5,914(2.10 \%)$ & $660 / 5,914(11.20 \%)$ & $115 / 5,914(2.60 \%)$ & $14 / 5,914(0.20 \%)$ & $1003 / 5,914(17.00 \%)$
\end{tabular}

Constituent ratio of: HSV II IgG in the two groups, $\chi^{2}=6.025, \mathrm{P}=0.014$ (continuity correction); HSV I IgG in the two groups, $\chi^{2}=0.071$, $\mathrm{P}=0.790$ (Pearson's $\chi^{2}$ ); RV IgG in the two groups, $\chi^{2}=1.574, \mathrm{P}=0.210$ (continuity correction); TOX IgG in the two groups, $\chi^{2}=0.000, \mathrm{P}=1.000$ (continuity correction); CMV IgG in the two groups, $\chi^{2}=1.873, \mathrm{P}=0.171$ (Pearson's $\chi^{2}$ ). IgG, immunoglobulin G; HSV, herpes simplex virus; $\mathrm{RV}$, rubella virus; TOX, toxoplasma; CMV, cytomegalovirus.

Table IV. Positive rates of anti-TORCH pathogen IgM antibodies in the cataract and control groups.

\begin{tabular}{|c|c|c|c|c|c|c|}
\hline Group & $\mathrm{N}$ & HSV II IgM & HSV I IgM & RV IgM & TOX IgM & CMV IgM \\
\hline Cataract group & 69 & $1 / 69(1.40 \%)$ & $1 / 69(1.40 \%)$ & $1 / 69(1.40 \%)$ & $0 / 69(0.00 \%)$ & $10 / 69(15.50 \%)$ \\
\hline Control group & 5,914 & $48 / 5,914(0.80 \%)$ & $28 / 5,914(0.50 \%)$ & $38 / 5,914(0.60 \%)$ & $2 / 5,914(0.00 \%)$ & $696 / 5,914(11.80 \%)$ \\
\hline
\end{tabular}

Constituent ratio of: HSV II IgM in the two groups, $\chi^{2}=0.000, \mathrm{P}=1.000$ (continuity correction); HSV I IgM in the two groups, $\chi^{2}=0.083$, $\mathrm{P}=0.773$ (continuity correction); RV IgM in the two groups, $\chi^{2}=0.006, \mathrm{P}=0.940$ (continuity correction); TOX IgM in the two groups, $\mathrm{P}=1.000$ (Fisher's Exact Test); CMV IgM in the two groups, $\chi^{2}=0.486, \mathrm{P}=0.486$ (Pearson's $\chi^{2}$ ). IgM, immunoglobulin M; HSV, herpes simplex virus; $\mathrm{RV}$, rubella virus; TOX, toxoplasma; CMV, cytomegalovirus.

Table V. Positive rates of anti-TORCH pathogen IgG antibodies in the monocular cataract and binocular cataract groups.

\begin{tabular}{lcccccc}
\hline Group & N & HSV II IgG & HSV I IgG & RV IgG & TOX IgG & CMV IgG \\
\hline Monocular cataract group & 32 & $2 / 32(6.30 \%)$ & $6 / 32(18.80 \%)$ & $4 / 32(12.50 \%)$ & $0 / 32(0.00 \%)$ & $5 / 32(15.60 \%)$ \\
Binocular cataract group & 37 & $3 / 37(8.10 \%)$ & $1 / 37(2.70 \%)$ & $0 / 37(0.00 \%)$ & $0 / 37(0.00 \%)$ & $11 / 37(29.70 \%)$
\end{tabular}

Constituent ratio of: HSV II IgG in the two groups, $\chi^{2}=0.000, \mathrm{P}=1.000$ (continuity correction); HSV I IgG in the two groups, $\chi^{2}=3.247, \mathrm{P}=0.072$ (continuity correction); RV IgG in the two groups, $\chi^{2}=2.887, \mathrm{P}=0.089$ (continuity correction); TOX IgG in the two groups. Constants can not calculate statistics; CMV IgG in the two groups, $\chi^{2}=1.917, \mathrm{P}=0.486$ (Pearson's $\chi^{2}$ ). IgG, immunoglobulin G; HSV, herpes simplex virus; $\mathrm{RV}$, rubella virus; TOX, toxoplasma; CMV, cytomegalovirus.

Table VI. Positive rates of anti-TORCH pathogen IgM antibodies in the monocular cataract and binocular cataract groups.

\begin{tabular}{lcccccr}
\hline Group & N & HSV II IgM & HSV I IgM & RV IgM & TOX IgM & CMV IgM \\
\hline Monocular cataract group & 32 & $1 / 32(3.10 \%)$ & $1 / 32(3.10 \%)$ & $0 / 32(0.00 \%)$ & $0 / 32(0.00 \%)$ & $5 / 32(15.60 \%)$ \\
Binocular cataract group & 37 & $0 / 37(0.00 \%)$ & $0 / 37(0.00 \%)$ & $1 / 37(2.70 \%)$ & $0 / 37(0.00 \%)$ & $10 / 37(14.50 \%)$ \\
\hline
\end{tabular}

Constituent ratio of: HSV II IgM in the two groups, P=0.464 (Fisher's Exact Test); HSV I IgM in the two groups, P=0.464 (Fisher's Exact Test); RV IgM in the two groups, $\mathrm{P}=1.000$ (Fisher's Exact Test); TOX IgM in the two groups. Constants can not calculate statistics; CMV IgM in the two groups, $\chi^{2}=0.000, \mathrm{P}=1.000$ (continuity correction). IgM, immunoglobulin M; HSV, herpes simplex virus; RV, rubella virus; TOX, toxoplasma; CMV, cytomegalovirus.

TORCH pathogen infections are a risk factor for congenital cataracts.

In order to correct for errors due to the small sample size and to verify the trends identified when comparing cases with congenital cataracts to unaffected cases, the present study used a large number of control samples from the outpatient children. As TORCH pathogen positivity rates were not high and the size of the cataract sample in this study was relatively small, the significance of the results were limited. The half-life of maternal anti-HSV IgG antibodies in the serum of children is unknown, and it may be expressed to higher levels in neonatal serum. Therefore, it may be possible to obtain more significant results by evaluating cataracts during the neonatal period. 


\section{References}

1. Dave A, Craig JE and Sharma S: The status of intercellular junctions in established lens epithelial cell lines. Mol Vis 18: 2937-2946, 2012.

2. Wang B, Wang KJ, Zhu SQ, Wang J and Ma X: Identification of the p. R $116 \mathrm{H}$ mutation in a chinese family with novel variable cataract phenotype: Evidence for a mutational hot spot in $\alpha \mathrm{A}$-crystallin gene. Ophthalmic Genet 33: 134-138, 2012.

3. Matoba A: Ocular viral infections. Pediatr Infect Dis 3: 358-368, 1984

4. Cotlier E: Congenital varicella cataract. Am J Ophthalmol 86: 627-629, 1978.

5. Lambert SR, Fernandes A, Drews-Botsch C and Boothe RG: Multifocal versus monofocal correction of neonatal monocular aphakia. J Pediatr Ophthalmol Strabismus 31: 195-201, 1994.

6. Barah F: Prevalence of herpes simplex types 1 and 2 , varicella zoster virus, cytomegalovirus, immunoglobulin $G$ antibodies among female university students in Syria. Saudi Med J 33: 990-994, 2012.

7. Akinbami AA, Adewunmi AA, Rabiu KA, Wright KO, Dosunmu AO, Dada MO and Adevemo TA: Seroprevalence of Toxoplasma gondii antibodies amongst pregnant women at the Lagos State University Teaching Hospital, Nigeria. Niger Postgrad Med J 17: 164-167, 2010.

8. Li Z, Yan C, Liu P, Yan R and Feng Z: Prevalence of serum antibodies to TORCH among women before pregnancy or in the early period of pregnancy in Beijing. Clin Chim Acta 403: 212-215, 2009.

9. Thaller R, Tammaro F and Pentimalli H: Risk factors for toxoplasmosis in pregnant women in central Italy. Infez Med 19: 241-247, 2011 (In Italian).

10. Mahalakshmi B, Therese KL, Devipriya U, Pushpalatha V, Margarita $S$ and Madhavan HN: Infectious aetiology of congenital cataract based on TORCHES screening in a tertiary eye hospital in Chennai, Tamil Nadu, India. Indian J Med Res 131: 559-564, 2010

11. Merdassi A, Limaiem R, Turki F, Chaker N, Falfoul Y, Mghaieth F, Korchane N and Matri LE: Ophthalmologic manifestations of congenital rubella. Arch Pediatr 18: 870-873, 2011 (In French)

12. Madhavan HN: Laboratory investigations on viral and chlamydia trachomatis infections of the eye: Sankara Nethralaya experiences. Indian J Ophthalmol 47: 241-246, 1999.

13. Raghu H, Subhan S, Jose RJ, Gangopadhyay N, Bhende J and Sharma S: Herpes simplex virus-1-associated congenital cataract. Am J Ophthalmol 138: 313-314, 2004.

14. Shyamala G, Sowmya P, Madhavan HN and Malathi J: Relative efficiency of polymerase chain reaction and enzyme-linked immunosorbant assay in determination of viral etiology in congenital cataract in infants. J Postgrad Med 54: 17-20, 2008.

15. Kuot A, Mills R, Craig JE, Sharma S and Burdon KP: Screening of the COL8A2 gene in an Australian family with early-onset Fuchs' endothelial corneal dystrophy. Clin Experiment Ophthalmol 42: 198-200, 2014.

16. Hutchison WM, Hay J, Lee WR and Siim JC: A study of cataract in murine congenital toxoplasmosis. Ann Trop Med Parasitol 76: 53-70, 1982.
17. Krummenacher C, Baribaud F, Ponce de Leon M, Baribaud I, Whitbeck JC, Xu R, Cohen GH and Eisenberg RJ: Comparative usage of herpesvirus entry mediator A and nectin-1 by laboratory strains and clinical isolates of herpes simplex virus. Virology 322 : 286-299, 2004

18. Lafaille FG, Pessach IM, Zhang SY, Ciancanelli MJ, Herman M, Abhyankar A, Ying SW, Keros S, Goldstein PA, Mostoslavsky G, et al: Impaired intrinsic immunity to HSV-1 in human iPSC-derived TLR3-deficient CNS cells. Nature 491: 769-773, 2012.

19. Newman $\mathrm{H}$ and Gooding C: Viral ocular manifestations: A broad overview. Rev Med Virol 23: 281-294, 2013.

20. Ashshi AM, Batwa SA, Kutbi SY, Malibary FA, Batwa M and Refaat B: Prevalence of 7 sexually transmitted organisms by multiplex real-time PCR in fallopian tube specimens collected from Saudi women with and without ectopic pregnancy. BMC Infect Dis 15: 569, 2015.

21. Malathi J, Therese KL and Madhavan HN: The association of rubella virus in congenital cataract-a hospital-based study in India. J Clin Virol 23: 25-29, 2001.

22. Ferrini W, Aubert V, Balmer A, Munier FL and Abouzeid H: Anterior uveitis and cataract after rubella vaccination: A case report of a 12-month-old girl. Pediatrics 132: e1035-e1038, 2013.

23. Vutova K, Peicheva Z, Popova A, Markova V, Mincheva N and Todorov T: Congenital toxoplasmosis: Eye manifestations in infants and children. Ann Trop Paediatr 22: 213-218, 2002.

24. Vandenbroucke S, Foets B, Wouters C and Casteels I: Bilateral congenital cataract with suspected lens-induced granulomatous uveitis. J AAPOS 18: 492-494, 2014.

25. Thibault M, Leydet J, Tournier-Lasserve E, Crow YJ, Rivier F, Echenne B, Langlois C, Daudet H, Sarda P and Roubertie A: Genetic syndromes that mimic congenital infections: Report of 2 cases. Arch Pediatr 18: 1297-1301, 2011 (In French).

26. Zhang J, Hu YZ, Xueli L, Li S, Wang M, Kong X, Li T, Shen P and Ma Y: The inhibition of CMV promoter by heat shock factor $4 \mathrm{~b}$ is regulated by Daxx. Int J Biochem Cell Biol 42: 1698-1707, 2010.

27. Tran TH, Bodaghi B, Rozenberg F, Cassoux N, Fardeau C and LeHoang P: Viral cause and management of necrotizing herpetic retinopathies. J Fr Ophtalmol 27: 223-236, 2004 (In French).

28. Chan WH, Biswas S, Ashworth JL and Lloyd IC: Congenital and infantile cataract: Aetiology and management. Eur J Pediatr 171: 625-630, 2012

29. Lito D, Francisco T, Salva I, Tavares Md, Oliveira R and Neto MT: TORCH serology and group B Streptococcus screening analysis in the population of a maternity. Acta Med Port 26: 549-554, 2013 (In Portuguese).

30. Vilibic-Cavlek T, Ljubin-Sternak S, Ban M, Kolaric B, Sviben M and Mlinaric-Galinovic G: Seroprevalence of TORCH infections in women of childbearing age in Croatia. J Matern Fetal Neonatal Med 24: 280-283, 2011.

31. Sen MR, Shukla BN and Tuhina B: Prevalence of serum antibodies to TORCH infection in and around Varanasi, Northern India. J Clin Diagn Res 6: 1483-1485, 2012.

32. Puccio G, Cajozzo C, Canduscio LA, Cino L, Romano A, Schimmenti MG, Giuffrè M and Corsello G: Epidemiology of toxoplasma and CMV serology and of GBS colonization in pregnancy and neonatal outcome in a Sicilian population. Ital J Pediatr 40: 23, 2014.

33. Maida JM, Mathers K and Alley CL: Pediatric ophthalmology in the developing world. Curr Opin Ophthalmol 19: 403-408, 2008. 